\title{
Chemical and Molecular Characterization of Crude Oil Obtained by Olive-Pomace Recentrifugation
}

\author{
Antonella Pasqualone, ${ }^{1}$ Valentina Di Rienzo, ${ }^{2}$ Wilma Sabetta, ${ }^{2}$ Valentina Fanelli, \\ Carmine Summo, ${ }^{1}$ Vito Michele Paradiso, ${ }^{1}$ Cinzia Montemurro, ${ }^{2,3}$ and Francesco Caponio ${ }^{1}$ \\ ${ }^{1}$ Department of Soil, Plant and Food Sciences, Section of Food Science and Technology, University of Bari Aldo Moro, \\ Via Amendola 165/A, 70125 Bari, Italy \\ ${ }^{2}$ Spin-Off Sinagri s.r.l., University of Bari Aldo Moro, Via Amendola 165/A, 70125 Bari, Italy \\ ${ }^{3}$ Department of Soil, Plant and Food Sciences, Section of Genetics and Breeding, University of Bari Aldo Moro, \\ Via Amendola 165/A, 70125 Bari, Italy \\ Correspondence should be addressed to Antonella Pasqualone; antonella.pasqualone@uniba.it
}

Received 11 October 2016; Accepted 6 December 2016

Academic Editor: Maria B. P. P. Oliveira

Copyright (C) 2016 Antonella Pasqualone et al. This is an open access article distributed under the Creative Commons Attribution License, which permits unrestricted use, distribution, and reproduction in any medium, provided the original work is properly cited.

\begin{abstract}
In oil-mills, olive-pomace recentrifugation is a common way to reduce pomace moisture and, at the same time, to recover the oil therein. According to current rules, the obtained oil is defined as "crude olive-pomace oil." The aim of this work is to verify the effect of recentrifugation on specific chemical and molecular parameters of the crude olive-pomace oil, by comparing it with the corresponding virgin olive oil obtained from the same olive lots. In particular, the following were considered: (i) the polar compounds of the oils that include compounds originated from oxidative and hydrolytic degradation, analyzed by highperformance size exclusion chromatography (HPSEC), and (ii) the profile of DNA microsatellite molecular markers that was analyzed by using the High Resolution Melting (HRM) technique. The obtained results evidenced the significantly higher hydrolytic degradation of crude olive-pomace oil, compared with the corresponding virgin olive oil, but at an extent unlikely able to allow the detection of fraudulent admixtures with virgin olive oils. In addition, the findings demonstrated the feasibility of the application of the HRM analysis of DNA microsatellites to crude olive-pomace oil, able to reveal the alteration of the declared varietal profile of a virgin olive oil sample by simply checking the HRM curve profiles.
\end{abstract}

\section{Introduction}

The processing technology of olive oil extraction has changed considerably during time. The discontinuous oil-extracting system based on the traditional hydraulic press has been replaced by the continuous plants that take advantage of the decanters, able to separate by centrifugation the oily phase from the other constituents (solid and aqueous phase) without any interruption. Over time, different types of centrifugal decanters have been designed and set up: 3phase; 3-phase without water addition (WWA); 2-phase; 3phase variable dynamic pressure (VDP); and 3-phase WWA pâté [1-3]. The 3-phase decanter produces high amounts of waste water, characterized by high contaminant capacity, due to the addition of warm water to olive paste prior to processing [2]. Developed with the aim of solving this problem, the successive 3-phase WWA-decanters avoid this inconvenience but lose oil yield, while the insertion of a variable dynamic pressure cone, as in the VDP-decanters, able to work with less diluted olive pastes, submits the olivepomace to an additional dynamic pressure allowing more oil to be recovered [1]. The most recent 3-phase WWA pâtédecanters show high extraction efficiency, due to a peculiar configuration able to separate olive oil from a solid residue at 50-55\% moisture and a semisolid by-product called "pâté," which contains waste water enriched by soft solids without pit fragments [3]. On the other hand, the older 2-phase decanters, which separate olive oil from a mixture of olivepomace and waste water, effectively reduce the amounts of waste water without losing oil yield [2]. 
All these systems coexist, but the 2-phase decanters, which are widely spread since the beginning of the nineties, still prevail [2], because they give oils with higher total phenol content and oxidation stability than those derived from the 3-phase decanters [4-6]. However, the 2-phase decanters produce a very humid olive-pomace (around 60\% moisture) [2] that, in order to extract the residual oil by means of lowpolarity solvents, needs to be dehydrated. Alternatively to the expensive heat drying, the olive millers frequently submit olive-pomace, after a brief kneading, to an additional centrifugation step. This simple physical treatment, commonly referred to as "recentrifugation" or "second centrifugation" to distinguish this operation by the precedent step of olive paste centrifugation aimed to produce virgin olive oils, is very effective in reducing the moisture content of olive-pomace and contemporarily allows to recover part of the residual oil [7]. The recovered oil is defined as "crude olive-pomace oil," according to the European Community Regulation number 1513/01 [8].

Several studies have been carried out to assess the chemical characteristics of crude olive-pomace oil obtained by pomace recentrifugation, focusing on the content of waxes, long-chain aliphatic aldehydes, alkyl esters, erythrodiol and uvaol, squalene, and phenolic compounds [9-12]. More recently, Caponio et al. [7] evidenced that the oil obtained by recentrifuging the olive-pomace shows higher content of carotenoids and chlorophylls and lower content of phenolic compounds than the corresponding virgin olive oil directly obtained from the first centrifugation of the olive paste, while the tocopherols and the antioxidant activity did not show significant differences.

The high-performance size exclusion chromatography (HPSEC) has been proved to be effective in detecting even low levels of polar compounds, including those originated from oxidative and hydrolytic degradation of the oils [13, 14]. These compounds, namely, triacylglycerol oligopolymers (TAGPs), oxidized triacylglycerols (ox-TAGs), and diacylglycerols (DAGs), are important nonconventional indices able to define the quality of both edible oils and food lipid fractions $[14,15]$ and could be useful to assess the degree of oxidative and hydrolytic degradation of crude olive-pomace oil.

In addition to the chemical characterization, which ascertains olive oil quality, the analysis of DNA-based molecular markers allows to verify the botanical and varietal authenticity of olive oil; see review by Pasqualone et al. [16]. This kind of analysis is currently being updated with very fast and effective techniques, such as High Resolution Melting (HRM), that very recently has been successfully applied to trace singlecultivar extra virgin olive oils [17], as well as olive pastes and virgin olive oils obtained by talc addition [18]. However, the reliability of this technique depends on many factors, including mechanical damage of DNA, and could be affected by the strong mechanical effect of the recentrifugation.

To the best of our knowledge, no study has been made to determine the polar compounds of crude olive-pomace oil or to assess the effectiveness of molecular marker analysis in this kind of oil. A better knowledge of the chemical and molecular characteristics of crude olive-pomace oil obtained by physical means could facilitate analytical checks when there is doubt of frauds involving the admixture with extra virgin olive oil. Therefore, the aim of this work has been to characterize the crude olive-pomace oil and to compare it with the corresponding virgin olive oil derived from the first centrifugation of the same olive paste. In particular, both chemical parameters related to oxidation and hydrolysis, that is, the HPSEC-analyzed polar compounds, and microsatellite molecular markers, analyzed by HRM, were considered.

\section{Materials and Methods}

2.1. Oil Production and Sampling. Oil production was performed in a local oil mill where the olives (Olea europaea L.), unwashed and after leaf-removal, were milled within $24 \mathrm{~h}$. A lot of approximately $3,000 \mathrm{~kg}$ of olives of Coratina cultivar was divided into two homogeneous batches, so as to carry out the whole experimental trial in duplicate (trial A and trial B).

The olives were processed using a hammer-crusher (Amenduni Nicola S.p.A., Modugno, Bari, Italy) operating at $2,800 \mathrm{rpm}$ and equipped with a grid having $5 \mathrm{~mm}$ diameter holes. The crushed paste was then transferred into the kneader (Amenduni Nicola S.p.A., Modugno, Bari, Italy). After kneading $\left(50 \mathrm{~min}\right.$ at $\left.22 \pm 1^{\circ} \mathrm{C}\right)$, the paste was pumped into a 2-phase horizontal centrifugal decanter (Taurus 902XX, Amenduni Nicola S.p.A., Modugno, Bari, Italy) operating at 2,800 rpm, with a processing capacity of $3,000 \mathrm{~kg} \mathrm{~h}^{-1}$. Finally, the oily phase was separated from any aqueous residue by centrifugation at $6,400 \mathrm{rpm}$ (vertical centrifuge, Alfa Laval, Tavarnelle Val di Pesa, Florence, Italy) and sampled (virgin olive oils A and B).

The residual olive-pomace of each of the two batches was kneaded (Amenduni Nicola S.p.A., Modugno, Bari, Italy) for $30 \mathrm{~min}$ at $22 \pm 1^{\circ} \mathrm{C}$, then subjected to recentrifugation by means of a 3-phase decanter (REX350, Amenduni Nicola S.p.A., Modugno, Bari, Italy) to collect the residual oil (crude olive-pomace oils A and B).

The whole procedure is schematized in Figure 1.

2.2. HPSEC Analysis of Polar Compounds. The polar compounds (PCs) were separated from the nonpolar compounds following AOAC analytical method as described in Paradiso et al. [19]. Then, the PCs were recovered in tetrahydrofuran (THF) and analyzed by means of HPSEC in order to separate the compound classes constituting them. The chromatographic system consisted of a Perkin-Elmer pump, series 200, a $50 \mu \mathrm{L}$ injector loop, a PL-gel guard column (Perkin-Elmer, Beaconsfield, UK) of $5 \mathrm{~cm}$ length $\times 7.5 \mathrm{~mm}$ i.d., and a series of two PL-gel columns (Perkin-Elmer, Beaconsfield, UK) of $7.5 \mathrm{~mm}$ i.d. $\times 30 \mathrm{~cm}$ in length each. The columns were packed with highly cross-linked styrene divinyl benzene copolymers with a particle diameter of $5 \mu \mathrm{m}$ and pore diameters of $500 \AA$. The detector was a differential refractometer (series 200A, Perkin-Elmer, Beaconsfield, UK). The elution solvent used was tetrahydrofuran for HPLC at a flow rate of $1.0 \mathrm{~mL} \mathrm{~min}^{-1}$. The identification and quantification of individual peaks were carried out as described in a previous paper [20]. The analytical determinations were performed in duplicate. 


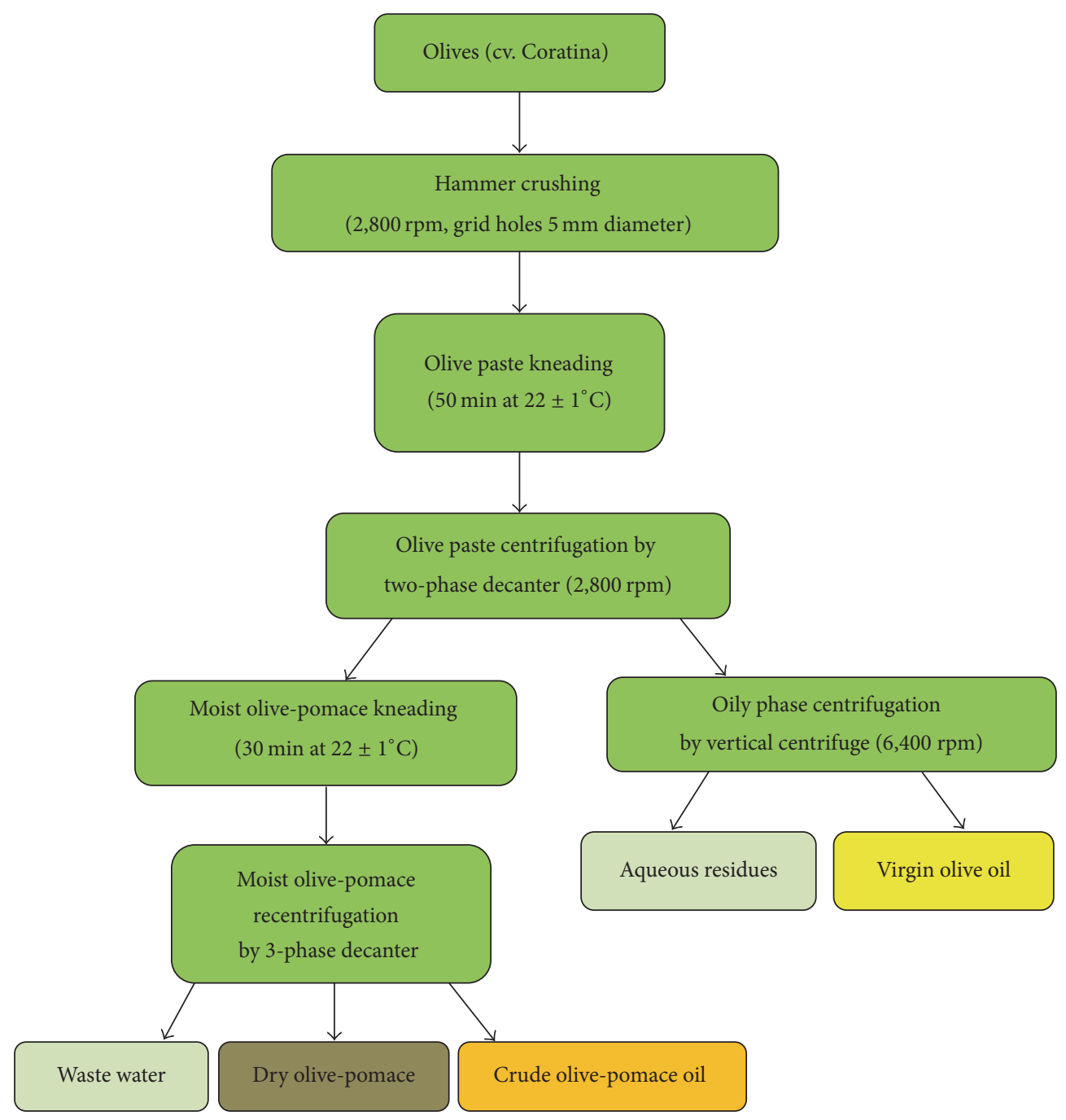

FIGURE 1: Flowchart of the productive process of virgin olive oil and crude olive-pomace oil.

2.3. DNA Extraction. DNA was extracted from olive oils as described in Pasqualone et al. [21], with the aid of the NucleoSpin $^{\circledR}$ Food kit (Macherey-Nagel GmbH \& Co., Düren, Germany). After extraction, effected in 3 replicates, DNA degradation level and concentration were assessed by both $0.8 \%$ agarose gel electrophoresis and spectrophotometric measure (Nano-Drop ${ }^{\mathrm{TM}}$ 2000C, Thermo Scientific, Wilmington, MA, USA) at $260 \mathrm{~nm}$. DNA purity was ascertained by determining the absorbance ratios $A_{260 / 280}$ and $A_{260 / 230}$.

2.4. HRM Analysis of Microsatellites. The amplification reactions of the extracted DNA were carried out according to the procedure described in previous papers [17, 18, 22], by using the olive microsatellite primer pairs DCA04, DCA09, and DCA14 [23]. HRM analyses were performed in triplicate on CFX96 Touch ${ }^{\mathrm{TM}}$ Real Time PCR Detection System (Bio-Rad, Hercules, CA, USA). Robust amplification curves, without nonspecific PCR products, were analyzed by CFX Manager ${ }^{\mathrm{TM}}$ software (Bio-Rad, Hercules, CA, USA). The melt curves were normalized along the temperature axis (temperature shifting) to permit easy discrimination of different DNA samples.

2.5. Statistical Analyses. Data were submitted to statistical analysis by XLStat software (Addinsoft SARL, New York, NY, USA). One-way analysis of variance (ANOVA) was performed, followed by the Tukey HSD test for multiple comparisons.

\section{Results and Discussion}

3.1. Chemical Determination of Oxidative and Hydrolytic Degradation. Figure 2 shows the results of the HPSEC analysis of PCs of virgin olive oil derived from the first centrifugation of olive paste and crude olive-pomace oil obtained from the same olive lots (mean values, standard deviations, and results of statistical analysis). The PCs are constituted by the main classes of substances of oxidation (TAGPs and ox-TAGs) and hydrolysis (DAGs) of triacylglycerols, 


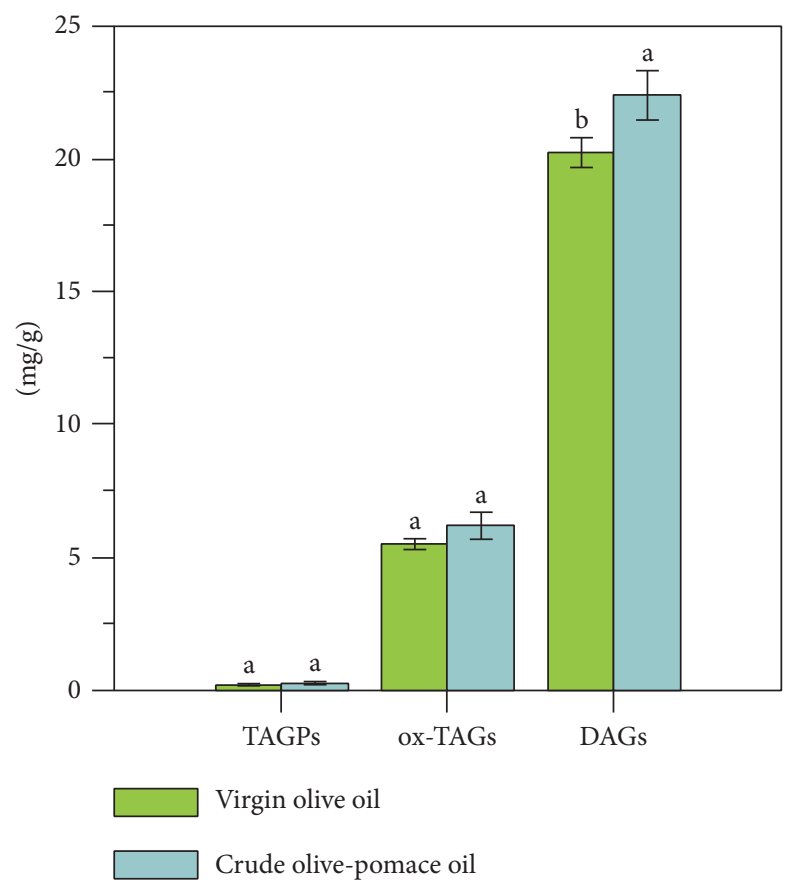

FIGURE 2: Results of the HPSEC analysis of polar compounds of the crude olive-pomace oil and the corresponding virgin olive oils obtained from the same olive lot (mean and standard deviations; $n=4$; i.e., 2 replicated oil production trials and 2 independent HPSEC analyses each). TAGPs = triacylglycerol oligopolymers; oxTAGs = oxidized triacylglycerols; DAGs = diacylglycerols . Different letters for the same parameter indicate significant differences at $p<$ 0.05 .

having higher polarity than unaltered triacylglycerols. In particular, the ox-TAGs have molecular weight very close to that of unaltered triacylglycerols and mainly consist of triacylglycerol hydroperoxides and triacylglycerols in which the hydroperoxydic functional group has been transformed in alcoholic or carbonyl group. The TAGPs have higher molecular weight than unaltered triacylglycerols because they are oligopolymeric end-products of oxidation that, being stable and nonvolatile, are considered very reliable indicators of oxidative degradation [14, 15].

The HPSEC analysis effectively separated these classes of compounds. As expected, the TAGPs were detected in very low amounts, since they are formed in oils only as a consequence of high temperatures such as those reached during bleaching and, above all, deodorization steps of the vegetable oil refining process $[20,24,25]$. No statistical differences were observed between virgin olive oil derived from the first centrifugation of olive paste and crude olive-pomace oil obtained, from the same olive lots, by recentrifuging the olive-pomace (Figure 2). In fact, the recentrifugation is a mechanical treatment that does not involve excessive heat stress.

On the contrary, higher values of both ox-TAGs and DAGs were detected in crude olive-pomace oil, although the difference with the corresponding virgin olive oil was significant $(p<0.05)$ only for DAGs, probably due to longer

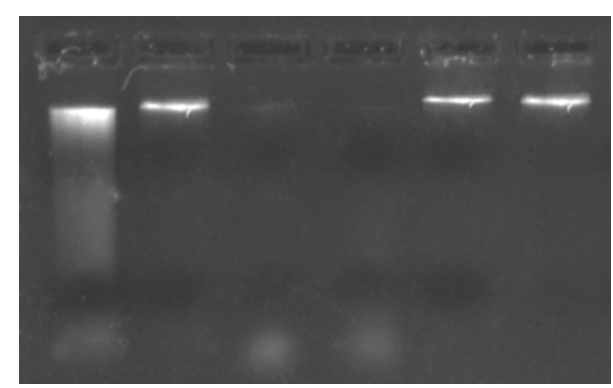

FIGURE 3: Agarose gel electrophoretic profile of DNA extracted from the oil samples under investigation. From the left to the right: virgin olive oil from "A" oil production trial; virgin olive oil from "B" oil production trial; crude olive-pomace oil from " $A$ " oil production trial; crude olive-pomace oil from "B" oil production trial; $50 \mathrm{ng} \lambda$ DNA ladder; $100 \mathrm{ng} \lambda$-DNA ladder.

processing time and consequent air-exposure to which olivepomace was subjected. However, the extent of the difference between the two oil types was limited and unable to allow detecting the presence of crude olive-pomace fraudulently added to virgin olive oil.

The levels of PCs observed in virgin olive oil samples were comparable to those usually found in previous works $[13,24]$. On the whole, the extent of the oxidative and hydrolytic degradation of the investigated crude olive-pomace oils ascertained by HPSEC analysis of PCs confirmed the results obtained in a previous research [7] by the conventional analyses foreseen by EC Reg. 2568/1991 [26] and subsequent modifications and integrations.

3.2. Molecular Characterization. Up to now, no study evaluated the effect of processing on the DNA present in crude olive-pomace oil. The repeated kneading and centrifugation of olive-pomace could involve severe fragmentation of nucleic acids and hamper DNA recovering and amplification. In fact, DNA was extracted from the cellular pellet obtained by centrifuging the oil samples, but in crude olive-pomace oil it was particularly scarce and not well visible by electrophoretic evaluation (Figure 3), evidencing the negative effect of the mechanical stress due to repeated processing steps. In addition, a relevant degradation affected the extracted DNA (especially evident in the samples from the " $\mathrm{A}$ " oil production trial), although not well appreciable in case of crude olive-pomace oil due to DNA scarcity.

Overall, significant differences in DNA extracting yield were observed between oils, with crude olive-pomace oil showing significantly lower $(p<0.05)$ extracting yield than the corresponding virgin olive oil (Table 1$)$.

The purity of the extracted DNA was also evaluated. In fact, besides DNA scarcity or degradation, another cause of false negatives in PCR analyses applied to foodstuffs can be the presence of interfering substances that can inhibit DNA polymerase [27]. In particular, the UV spectrophotometer $A_{260 / 230}$ ratio, useful to evaluate the presence of lipids and phenolic compounds, and the $A_{260 / 280}$ ratio, which ascertains the presence of proteins [28], were determined. 
TABLE 1: DNA extraction yield and spectrophotometric absorption ratios of crude olive-pomace oil and the corresponding virgin olive oil (mean and standard deviations; $n=6$; i.e., 2 replicated oil production trials and 3 independent DNA extractions each). Different superscript letters in the same column indicate significant differences at $p<0.05$.

\begin{tabular}{lccc}
\hline & Yield (ng DNA/mg sample) & $A_{260 / 230}$ & $A_{260 / 280}$ \\
\hline Crude olive-pomace oil & $10^{\mathrm{b}} \pm 2$ & $1.49^{\mathrm{a}} \pm 0.03$ & $1.66^{\mathrm{a}} \pm 0.05$ \\
Virgin olive oil & $45^{\mathrm{a}} \pm 6$ & $1.46^{\mathrm{a}} \pm 0.02$ & $1.64^{\mathrm{a}} \pm 0.04$ \\
\hline
\end{tabular}

The $A_{260 / 230}$ ratio was lower than the optimal value of 2.0 both in virgin olive oils and in crude olive-pomace oils (Table 1), probably due to the residual presence of polyphenols, polar molecules partly soluble in the buffers present in the commercial kit adopted for DNA extraction [29]. Phenolic compounds, in fact, are known to be present in olive oils in general and are particularly concentrated in oils obtained from cv. Coratina [7], such as those used in this research. The observed values for $A_{260 / 230}$ ratio were in the range determined in DNA from olive oils in a previous research [18] when, despite being below the optimal value, they did not prevent amplification. No significant differences were observed between crude olive-pomace oils and the corresponding virgin olive oils, in spite of the fact that oils derived from olive-pomace have been reported to contain lower amounts of total phenols than virgin olive oils $[7,9,12]$.

The absorbance ratio at $260 / 280 \mathrm{~nm}$, instead, was very close to the optimal value of 1.7 typical of pure DNA [28]. This result was expected due to the almost total absence of proteins in the food matrix considered. No significant differences were observed between crude olive-pomace oils and the corresponding virgin olive oils (Table 1).

The extracted DNA was then submitted to PCR by amplifying a set of 3 microsatellite markers selected in previous works for their high reproducibility and small size of the target sequence $[21,30]$, able to facilitate the amplification of degraded DNA. In particular, these microsatellites were analyzed by means of the HRM technique, known to be applicable to DNA extracted from virgin olive oils $[17,18,31,32]$. By monitoring the fluorescence decrease due to the release of intercalating fluorescent dyes during thermal denaturation (melting) of double stranded DNA, HRM allows the detection of polymorphism between samples based on differences in the melting temperature of PCR products and can detect differences in DNA as low as a single nucleotide [33]. In addition, HRM detects more polymorphisms than conventional electrophoresis of microsatellite amplicons, because it reveals also the presence of single nucleotide polymorphisms (SNPs) in the region flanking the microsatellite repeats. Hence, HRM curves can be different in shape even in case of monomorphic markers and this magnifies the polymorphism degree of microsatellites [34].

Figure 4 shows the temperature-shifted normalized HRM curves of PCR products obtained by amplifying DCA04, DCA09, and DCA14 microsatellites in crude olive-pomace oil and in the corresponding virgin olive oil. Each group of four almost overlapping curves corresponds to a different microsatellite. Within the same group, each single curve corresponds to one out of four different samples amplified:

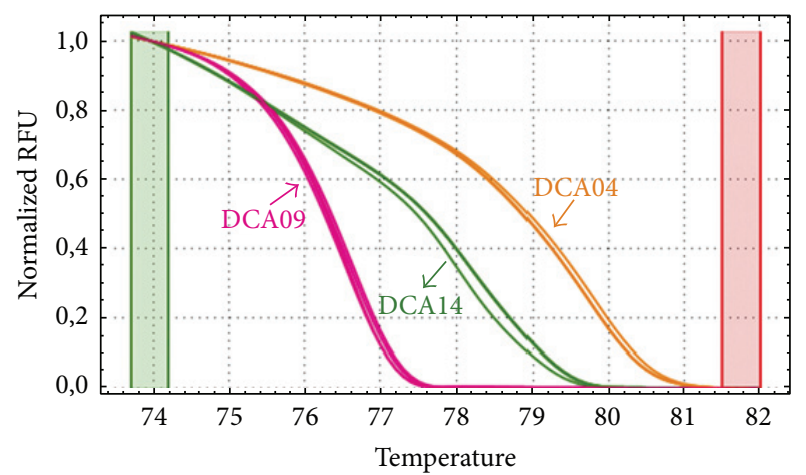

FIGURE 4: Temperature-shifted normalized HRM curves of PCR products obtained by amplifying DCA04, DCA09, and DCA14 microsatellites in crude olive-pomace oil and in the corresponding virgin olive oil.

virgin olive oil and crude olive-pomace oil from both "A" and "B" oil production trials. Consistent amplifications were obtained for all the samples. In addition, by comparing the shape of curves depicted by temperature-shifted melting curves it can be observed that, for the same microsatellite, the different samples analyzed showed almost identical HRM profiles. These findings confirmed the genetic homogeneity of the olive lot processed (cv. Coratina) and evidenced the same ability of DNA from crude olive-pomace oil and from virgin olive oil in being analyzed by HRM analysis of microsatellites.

However, from a practical point of view, this result implies that, assuming that virgin olive oil and crude olive-pomace oil are from the same cultivar or varietal blend, they are undistinguishable by microsatellite HRM analysis. Only in case that crude olive-pomace oil is from a different cultivar, then microsatellites can reveal the alteration of the declared varietal profile of a virgin olive oil sample.

\section{Conclusion}

The obtained results evidenced the significantly higher hydrolytic degradation of crude olive-pomace oil, compared with the corresponding virgin olive oil, but at an extent unlikely able to allow the detection of fraudulent admixtures with virgin olive oils. In addition, the findings demonstrated the feasibility of the application of the HRM analysis of DNA microsatellites to crude olive-pomace oil, able to reveal the alteration of the declared varietal profile of a virgin olive oil sample by simply checking the HRM curve profiles.

Each technique is characterized by strengths and weaknesses. An integrated analytical approach aimed to solve 
the doubt of frauds involving the admixture of crude olivepomace oil with virgin olive oil could take advantage of chemical analyses other than HPSEC of PCs, coupled with molecular techniques.

\section{Competing Interests}

The authors declare that there is no conflict of interests regarding the publication of this paper.

\section{References}

[1] R. Amirante, E. Cini, G. L. Montel, and A. Pasqualone, "Influence of mixing and extraction parameters on virgin olive oil quality," Grasas y Aceites, vol. 52, no. 3-4, pp. 198-201, 2001.

[2] M. Uceda, A. Jiménez, and G. Beltrán, "Olive oil extraction and quality," Grasas y Aceites, vol. 57, no. 1, pp. 25-31, 2006.

[3] A. Leone, R. Romaniello, R. Zagaria, and A. Tamborrino, "Mathematical modelling of the performance parameters of a new decanter centrifuge generation," Journal of Food Engineering, vol. 166, pp. 10-20, 2015.

[4] F. Angerosa and L. Di Giovacchino, "Natural antioxidants of virgin olive oil obtained by two and tri-phase centrifugal decanters," Grasas y Aceites, vol. 47, no. 4, pp. 247-254, 1996.

[5] G. De Stefano, P. Piacquadio, M. Servili, L. Di Giovacchino, and V. Sciancalepore, "Effect of extraction systems on the phenolic composition of virgin olive oils," Fett/Lipid, vol. 101, no. 9, pp. 328-332, 1999.

[6] F. Caponio, C. Summo, V. M. Paradiso, and A. Pasqualone, "Influence of decanter working parameters on the extra virgin olive oil quality," European Journal of Lipid Science and Technology, vol. 116, no. 12, pp. 1626-1633, 2014.

[7] F. Caponio, G. Squeo, J. I. Monteleone, V. M. Paradiso, A. Pasqualone, and C. Summo, "First and second centrifugation of olive paste: Influence of talc addition on yield, chemical composition and volatile compounds of the oils," LWT-Food Science and Technology, vol. 64, no. 1, pp. 439-445, 2015.

[8] European Council, "Council Regulation (EC) No 1513/2001 of 23 July 2001 amending Regulations No 136/66/EEC and (EC) No 1638/98 as regards the extension of the period of validity of the aid scheme and the quality strategy for olive oil," Official Journal of European Communities, vol. L 201, pp. 4-7, 2001.

[9] J. Alba Mendoza, F. Hidalgo Casado, M. A. Ruiz Gomez et al., "Características de los aceites de olive de primera y segunda centrifugacion," Grasas y Aceites, vol. 47, no. 3, pp. 163-181, 1996.

[10] L. Cerretani, A. Bendini, E. Valli, E. Chiavaro, G. Morchio, and G. Lercker, "Chemical characterization of refined olive oils and second extraction olive oils ("repaso" oils) available on the national and international markets," La Rivista Italiana delle Sostanze Grasse, vol. 88, no. 2, pp. 82-88, 2011.

[11] E. Chiavaro, L. Cerretani, A. Bendini, M. Rinaldi, and G. Lercker, "DSC characterization of different products by olive oil processing," Rivista Italiana delle Sostanze Grasse, vol. 88, no. 3, pp. 182-190, 2011.

[12] M. Hermoso, M. Uceda, A. García-Ortiz, A. Jimenez, and G. Beltrán, "Second centrifugation of olive paste. Oil recuperation percent and olive oil characterization," Acta Horticolturae, vol. 474, pp. 721-724, 1997.

[13] F. Caponio, M. T. Bilancia, A. Pasqualone, E. Sikorska, and T. Gomes, "Influence of the exposure to light on extra virgin olive oil quality during storage," European Food Research and Technology, vol. 221, no. 1, pp. 92-98, 2005.

[14] F. Caponio, C. Summo, M. T. Bilancia, V. M. Paradiso, E. Sikorska, and T. Gomes, "High performance size-exclusion chromatography analysis of polar compounds applied to refined, mild deodorized, extra virgin olive oils and their blends: an approach to their differentiation," LWT-Food Science and Technology, vol. 44, no. 8, pp. 1726-1730, 2011.

[15] F. Caponio, T. Gomes, A. Pasqualone, and C. Summo, "Use of the high performance size exclusion chromatography analysis for the measurement of the degree of hydrolytic and oxidative degradation of the lipid fraction of biscuits," Food Chemistry, vol. 102, no. 1, pp. 232-236, 2007.

[16] A. Pasqualone, C. Montemurro, V. di Rienzo, C. Summo, V. M. Paradiso, and F. Caponio, "Evolution and perspectives of cultivar identification and traceability from tree to oil and table olives by means of DNA markers," Journal of the Science of Food and Agriculture, vol. 96, no. 11, pp. 3642-3657, 2016.

[17] C. Montemurro, M. M. Miazzi, A. Pasqualone, V. Fanelli, W. Sabetta, and V. Di Rienzo, "Traceability of PDO olive oil 'Terra di Bari' using high resolution melting," Journal of Chemistry, vol. 2015, Article ID 496986, 7 pages, 2015.

[18] A. Pasqualone, V. Di Rienzo, M. M. Miazzi, V. Fanelli, F. Caponio, and C. Montemurro, "High resolution melting analysis of DNA microsatellites in olive pastes and virgin olive oils obtained by talc addition," European Journal of Lipid Science and Technology, vol. 117, no. 12, pp. 2044-2048, 2015.

[19] V. M. Paradiso, F. Caponio, G. Bruno, A. Pasqualone, C. Summo, and T. Gomes, "Complex role of monoacylglycerols in the oxidation of vegetable oils: different behaviors of soybean monoacylglycerols in different oils," Journal of Agricultural and Food Chemistry, vol. 62, no. 44, pp. 10776-10782, 2014.

[20] T. Gomes and F. Caponio, "Investigation on the degree of oxidation and hydrolysis of refined olive oils. An approach for better product characterisation," Italian Journal of Food Science, vol. 9, no. 4, pp. 277-285, 1997.

[21] A. Pasqualone, V. Di Rienzo, A. Blanco, C. Summo, F. Caponio, and C. Montemurro, "Characterization of virgin olive oil from Leucocarpa cultivar by chemical and DNA analysis," Food Research International, vol. 47, no. 2, pp. 188-193, 2012.

[22] V. di Rienzo, M. M. Miazzi, V. Fanelli et al., "An enhanced analytical procedure to discover table grape DNA adulteration in industrial musts," Food Control, vol. 60, pp. 124-130, 2016.

[23] K. M. Sefc, M. S. Lopes, D. Mendoça, M. Rodrigues Dos Santos, M. Laimer Da Câmara Machado, and A. Da Câmara Machado, "Identification of microsatellite loci in olive (Olea europaea L.) and their characterization in Italian and Iberian olive trees," Molecular Ecology, vol. 9, pp. 1171-1173, 2000.

[24] M. T. Bilancia, F. Caponio, E. Sikorska, A. Pasqualone, and C. Summo, "Correlation of triacylglycerol oligopolymers and oxidised triacylglycerols to quality parameters in extra virgin olive oil during storage," Food Research International, vol. 40, no. 7, pp. 855-861, 2007.

[25] T. Gomes, F. Caponio, V. Durante, C. Summo, and V. M. Paradiso, "The amounts of oxidized and oligopolymeric triacylglycerols in refined olive oil as a function of crude oil oxidative level," LWT-Food Science and Technology, vol. 45, no. 2, pp. 186190, 2012.

[26] European Commission, "Commission Regulation (EEC) No. $2568 / 91$ on the characteristics of olive oil and olive-residue oil and on the relevant methods of analysis," Official Journal of the European Communities, vol. 248, pp. 1-83, 1991. 
[27] I. G. Wilson, "Inhibition and facilitation of nucleic acid amplification," Applied and Environmental Microbiology, vol. 63, no. 10, pp. 3741-3751, 1997.

[28] C. Yeates, M. R. Gillings, A. D. Davison, N. Altavilla, and D. A. Veal, "Methods for microbial DNA extraction from soil for PCR amplification," Biological Procedures Online, vol. 1, no. 1, pp. 4047, 1998.

[29] Macherey-Nagel, Genomic DNA from Food. User Manual NucleoSpin ${ }^{\circledR}$ Food, Macherey-Nagel, Düren, Germany, 2012.

[30] A. Pasqualone, V. Di Rienzo, R. Nasti, A. Blanco, T. Gomes, and C. Montemurro, "Traceability of Italian Protected Designation of Origin (PDO) table olives by means of microsatellite molecular markers," Journal of Agricultural and Food Chemistry, vol. 61, no. 12, pp. 3068-3073, 2013.

[31] M. Vietina, C. Agrimonti, and N. Marmiroli, "Detection of plant oil DNA using high resolution melting (HRM) post PCR analysis: a tool for disclosure of olive oil adulteration," Food Chemistry, vol. 141, no. 4, pp. 3820-3826, 2013.

[32] I. Ganopoulos, C. Bazakos, P. Madesis, P. Kalaitzis, and A. Tsaftaris, "Barcode DNA high-resolution melting (Bar-HRM) analysis as a novel close-tubed and accurate tool for olive oil forensic use," Journal of the Science of Food and Agriculture, vol. 93, no. 9, pp. 2281-2286, 2013.

[33] G. H. Reed, J. O. Kent, and C. T. Wittwer, "High-resolution DNA melting analysis for simple and efficient molecular diagnostics," Pharmacogenomics, vol. 8, no. 6, pp. 597-608, 2007.

[34] A. Xanthopoulou, I. Ganopoulos, G. Koubouris et al., "Microsatellite high-resolution melting (SSR-HRM) analysis for genotyping and molecular characterization of an Olea europaea germplasm collection," Plant Genetic Resources, vol. 12, no. 3, pp. 273-277, 2014. 

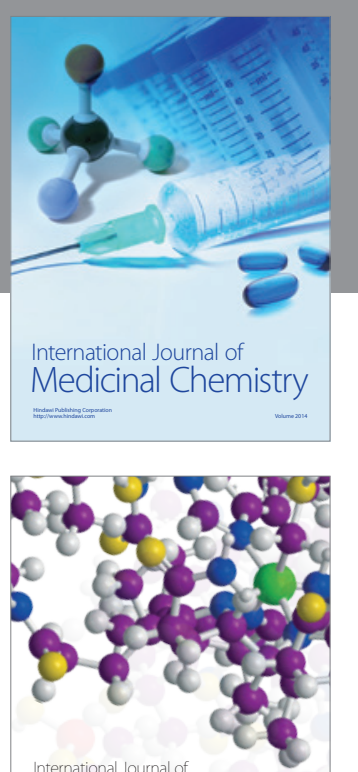

Carbohydrate Chemistry

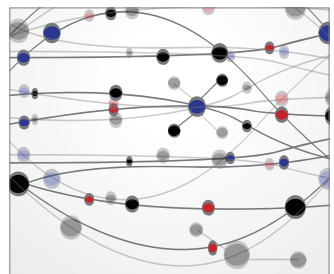

The Scientific World Journal
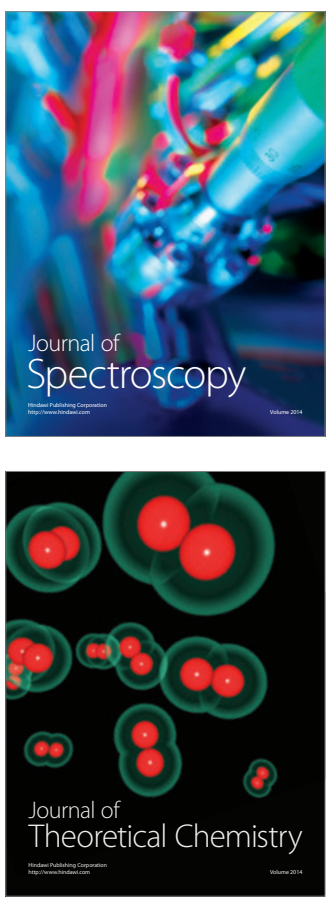
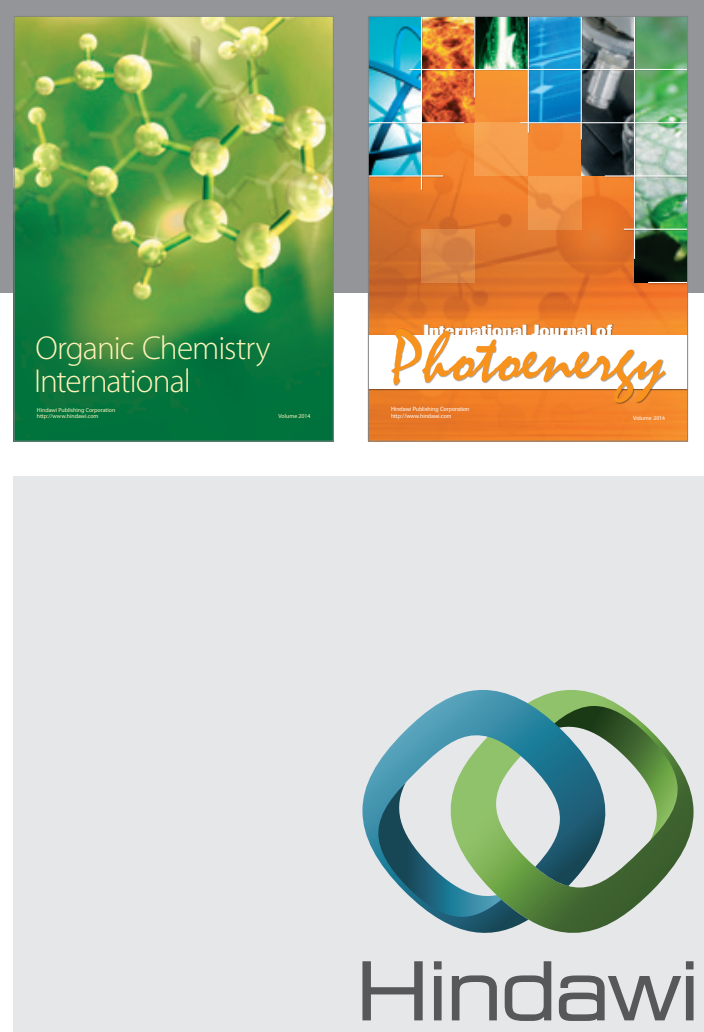

Submit your manuscripts at

http://www.hindawi.com

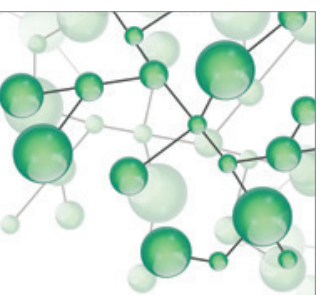

International Journal of

Inorganic Chemistry

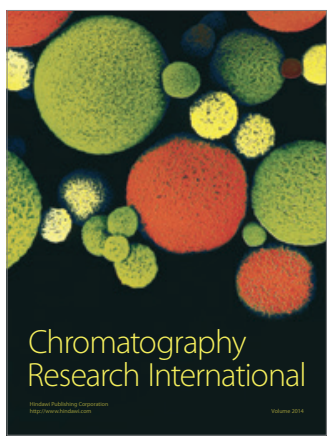

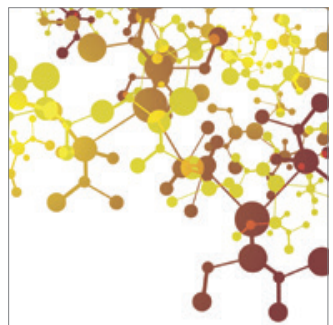

Applied Chemistry
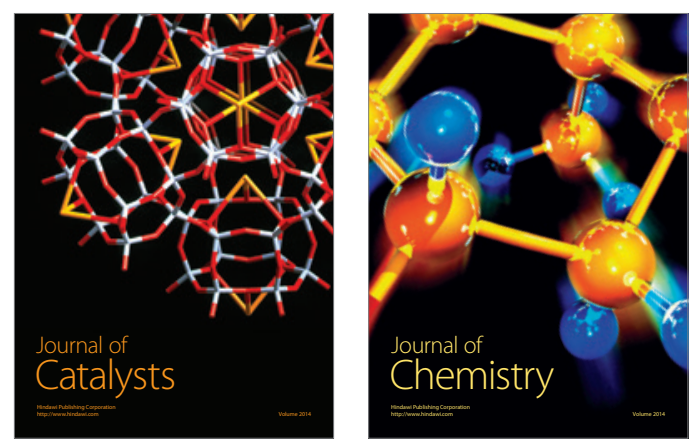
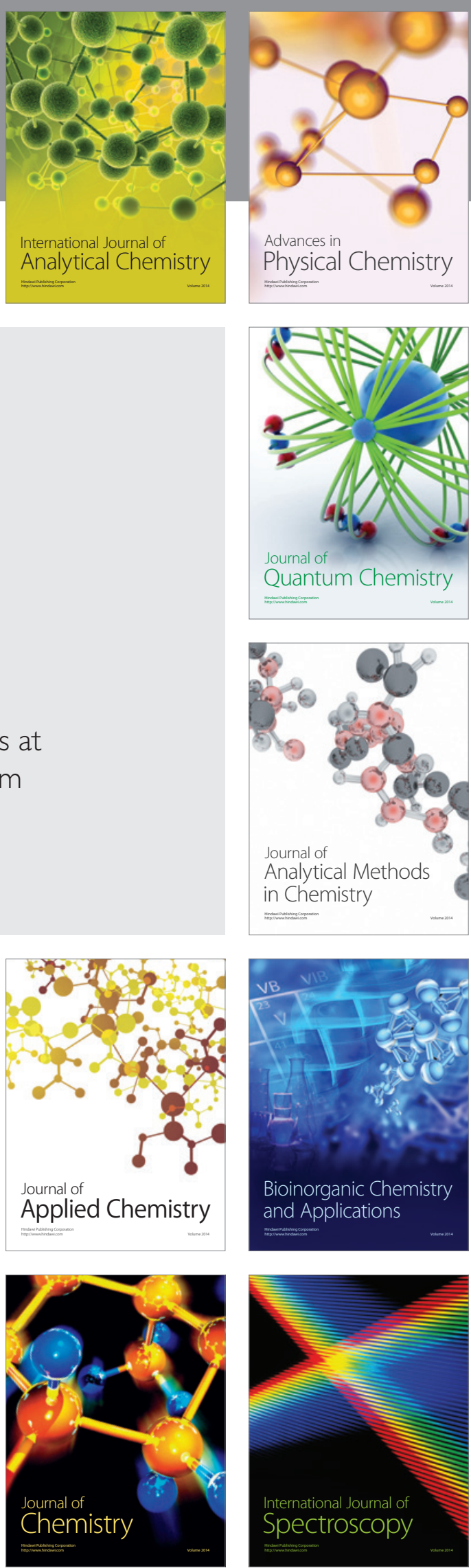